\title{
Fission Products
}

\section{Distribution in TRISO Coated Fuel Particles Irradiated to \\ $3.22 \times 10^{21} \mathrm{n} / \mathrm{cm}^{2}$ Fast Fluence at $1092^{\circ} \mathrm{C}$}

\section{ASME 2015 Nuclear Forum (NUCLRF2015)}

The INL is a

U.S. Department of Energy

National Laboratory

operated by

Battelle Energy Alliance

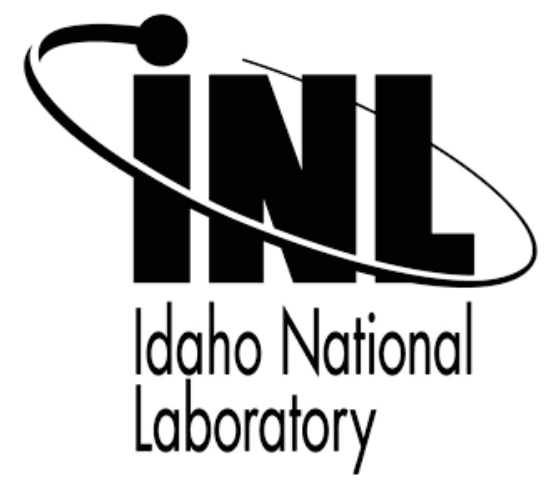

\section{Haiming Wen, Isabella J. Van Rooyen, Connie M. Hill, Tammy L. Trowbridge, Ben D. Coryell}

June 2015

This is a preprint of a paper intended for publication in a journal or proceedings. Since changes may be made before publication, this preprint should not be cited or reproduced without permission of the author. This document was prepared as an account of work sponsored by an agency of the United States Government. Neither the United States Government nor any agency thereof, or any of their employees, makes any warranty, expressed or implied, or assumes any legal liability or responsibility for any third party's use, or the results of such use, of any information, apparatus, product or process disclosed in this report, or represents that its use by such third party would not infringe privately owned rights. The views expressed in this paper are not necessarily those of the United States Government or the sponsoring agency. 

NUCLRF2015-49695

\section{FISSION PRODUCTS DISTRIBUTION IN TRISO COATED FUEL PARTICLES IRRADIATED TO $3.22 \times 10^{21} \mathrm{~N} / \mathrm{CM}^{2}$ FAST FLUENCE AT $1092^{\circ} \mathrm{C}$}

\author{
Haiming Wen \\ Idaho National Laboratory \\ Idaho Falls, Idaho, USA
}

\author{
Isabella J. Van Rooyen * \\ Idaho National Laboratory \\ Idaho Falls, Idaho, USA
}

\author{
Connie M. Hill \\ Idaho National Laboratory \\ Idaho Falls, Idaho, USA
}

\author{
Tammy L. Trowbridge \\ Idaho National Laboratory \\ Idaho Falls, Idaho, USA
}

\author{
Ben D. Coryell \\ Idaho National Laboratory \\ Idaho Falls, Idaho, USA
}

\section{ABSTRACT}

Mechanisms by which fission products (especially silver $[\mathrm{Ag}]$ ) migrate across the coating layers of tristructural isotropic (TRISO) coated fuel particles designed for next generation nuclear reactors have been the subject of a variety of research activities due to the complex nature of the migration mechanisms. This paper presents results obtained from the electron microscopic examination of selected irradiated TRISO coated particles from fuel compact 1-3-1 irradiated in the first Advanced Gas Reactor experiment (AGR-1) that was performed as part of the Next Generation Nuclear Plant (NGNP) project. It is of specific interest to study particles of this compact as they were fabricated using a different carrier gas composition ratio for the $\mathrm{SiC}$ layer deposition compared with the baseline coated fuel particles reported on previously. Basic scanning electron microscopy (SEM) and SEM montage investigations of the particles indicate a correlation between the distribution of fission product precipitates and the proximity of the inner pyrolytic carbon (IPyC)-silicon carbide ( $\mathrm{SiC}$ ) interface to the fuel kernel. Transmission electron microscopy (TEM) samples were sectioned by focused ion beam (FIB) technique from the IPyC layer, the SiC layer and the IPyC-SiC interlayer of the coated fuel particle. Detailed TEM and scanning transmission electron microscopy (STEM) coupled with energy dispersive X-ray spectroscopy (EDS) were performed to identify fission products and characterize their distribution across the IPyC and $\mathrm{SiC}$ layers in the areas examined. Results indicate the presence of palladium-siliconuranium (Pd-Si-U), Pd-Si, Pd-U, Pd, U, U-Si precipitates in the $\mathrm{SiC}$ layer and the presence of $\mathrm{Pd}-\mathrm{Si}-\mathrm{U}, \mathrm{Pd}-\mathrm{Si}, \mathrm{U}-\mathrm{Si}, \mathrm{U}$ precipitates in the IPyC layer. No Ag-containing precipitates are evident in the IPyC or $\mathrm{SiC}$ layers. With increased distance from the IPyC-SiC interface, there are less U-containing precipitates, however, such precipitates are present across nearly the entire $\mathrm{SiC}$ layer.

\section{KEYWORDS}

TRISO fuel particles; irradiation; fission product; transport

* Corresponding author. Tel.: +1 2085264199.

E-mail address: isabella.vanrooyen@inl.gov (I.J. van Rooyen).

\section{INTRODUCTION}

Tristructural isotropic (TRISO) coated fuel particles are designed for use as nuclear fuel particles in high temperature nuclear reactors (HTR). They are composed of a uranium oxide $\left(\mathrm{UO}_{2}\right)$ or uranium oxy-carbide (UCO) fuel kernel protected by a series of ceramic coating layers that retain fission products. The ceramic TRISO coatings are a finely-tuned fission product containment system, which consist of, in the order of increased distance to the fuel kernel, a porous carbon (C) buffer layer, a relatively dense IPyC layer, a high-strength $\mathrm{SiC}$ layer, and an outer $\mathrm{PyC}(\mathrm{OPyC})$ layer $[1,2]$. The $\mathrm{SiC}$ layer is the primary fission product barrier of the TRISO particle and serves as the principal structural layer as well.

Release of certain metallic fission products e.g. $\mathrm{Ag}$ and $\mathrm{Pd}$, through intact TRISO coatings has been evident for decades around the world [3-5], as well as in the recent AGR-1 experiment at Idaho National Laboratory (INL) [1]. The release of ${ }^{110 \mathrm{~m}} \mathrm{Ag}$ is a potential worker safety concern due to plate-out on the cooler metallic parts of the helium pressure boundary. This safety concern highlights the importance of identifying the metallic fission product transport mechanisms of ${ }^{110 \mathrm{~m}} \mathrm{Ag}$ through the TRISO coating layers. In the past 40 years, numerous studies, including reactor experiments, out-of-pile experiments, and simulations, have been performed to 
investigate the fission product transport behavior and mechanisms [6, 7]. The previous studies, however, have not been able to reproduce the observed transport behavior of fission products and the mechanisms remain poorly understood. Therefore, the first direct measurement of $\mathrm{Ag}$ in $\mathrm{SiC}$ grain boundaries of neutron irradiated TRISO coated particles from the AGR-1 experiment [8] provided a benchmark to understand $\mathrm{Ag}$ transport mechanism. In addition, $\mathrm{Pd}$ was observed to coalesce at the IPyC-SiC interface during irradiation of the $\mathrm{UO}_{2}$ TRISO coated particles [9-11]. Recent post-irradiation examination test results from AGR-1 showed no significant chemical interaction between $\mathrm{Pd}$ and $\mathrm{SiC}$ for UCO TRISO coated particles [12]. However, some research has found that Pd may assist Ag transport [13-14]. These results focused INL's analytical electron microscopy investigation on $\mathrm{Pd}$ and $\mathrm{Ag}$ transport in neutron irradiated TRISO coated particles.

The different fuel variants, i.e., different processing parameters and accordingly different microstructure of the TRISO coating layers, may influence fission product transport. The advanced microscopy performed during AGR-1 postirradiation examination (PIE) to date has been largely focused on TRISO coated particles with the baseline variant fuel type $[8,12]$, with limited electron microscopic results reported on other variant fuel types, e.g., variant 3 fuel [14]. This paper presents results obtained from the electron microscopic examination of selected irradiated TRISO coated particles from fuel Compact 1-3-1 of AGR-1, which have variant 3 fuel. Variant 3 fuel is described in detail in the Materials and Methods section. The focus of this paper is on the spatial distribution and composition of the fission products.

\section{MATERIALS AND METHODS}

\section{Materials}

SEM and TEM results on a coated particle from Compact 1-3-1 of AGR-1 are described herein. The unique compact identification number, 1-3-1 is based on the specific capsule, level, and stack number for each compact. Compact 1-3-1 refers to the compact in Capsule 1 at Level 3 of Stack 1. The capsule design and details of the AGR-1 experiment have been described previously [1].

Compact 1-3-1 contains variant 3 fuel particles fabricated with carrier gas composition for the $\mathrm{SiC}$ layer vapor deposition altered from 100\% hydrogen (used for AGR-1 baseline fuel) to a $50 \%$ argon - 50\% hydrogen mixture and the deposition temperature lowered relative to the baseline (from $1500{ }^{\circ} \mathrm{C}$ to $1425^{\circ} \mathrm{C}$ ). These changes were expected to reduce the potential for $\mathrm{SiC}$ defects resulting from uranium dispersion and provide a variation in $\mathrm{SiC}$ microstructure that may be less permeable to metallic fission products. The fuel kernel is low-enriched UCO with a diameter of approximately $350 \mu \mathrm{m}$. Variant 3 AGR-1 coated particles have average thicknesses of $\sim 104, \sim 39, \sim 36$ and $\sim 39 \mu \mathrm{m}$ for buffer, IPyC, $\mathrm{SiC}$ and OPyC layers, respectively [15].

Compact 1-3-1 was irradiated to $15.3 \%$ fissions per initial metal atom (FIMA) average burnup, $1092^{\circ} \mathrm{C}$ time-average volume-averaged temperature, $1166{ }^{\circ} \mathrm{C}$ time-average peak temperature and an average fast fluence of $3.22 \times 10^{21} \mathrm{n} / \mathrm{cm}^{2}$. Individual particles were examined by a precision gamma scanner (PGS) to measure the activity of various gamma ray emitting fission products. The retention of ${ }^{110 \mathrm{~m}} \mathrm{Ag}$ in each particle is estimated by comparing the measured inventory to the predicted inventory normalized by the relative Cs-137 activity to account for the influence of different kernel sizes (see [1] for details).

The measured-to-calculated ratio for fuel particle 99 from Compact 1-3-1 (designated as AGR1-131-099) is 0.15. In general, this ratio for particles from Compact 1-3-1 is on this order. Hence, there was actually high release of $\mathrm{Ag}$ from the particles in this compact.

\section{Methods}

A JEOL 7000 field-emission-gun (FEG) microscope is used for the SEM studies. Backscattered electron images and secondary electron images were recorded. An image montage was made by capturing sequential backscattered electron micrographs of the IPyC-SiC interface at 4000x magnification, ensuring that there is adequate overlap between adjacent images to stitch them together. Adobe Photoshop was used to combine the $\sim 80$ images by overlapping shared features within images to form a complete image montage of the IPyC-SiC interface [12].

The STEM specimens were prepared at the Electron Microscopy Laboratory (EML) at the Materials and Fuels Complex (MFC) of INL using the dual-beam Quanta 3D FEG FIB. Figure 1 shows the locations where TEM lamellae were sectioned by FIB. Lamella 1 was extracted from a location parallel to the SiC-IPyC interface, and Lamella 5 was perpendicular to the interface and contains parts of both the IPyC and SiC layers. Lamellae 2, 3 and 4 were sectioned from locations in the $\mathrm{SiC}$ layer along the radial direction, with increased distance from the SiC-IPyC interface. In this paper, the results obtained from examining the FIB lamellae 5, 2 and 3 are described and discussed. STEM and EDS were conducted with a FEI Tecnai G2 F30 TEM at the Microscopy and Characterization Suite (MaCS) of Center for Advanced Energy Studies (CAES) at INL, where irradiated materials with low activity can be examined. The extremely small volume of the FIB-prepared lamellae minimizes the irradiation dose to a level that allows for the use of these advanced techniques for the irradiated TRISO coated particles. 


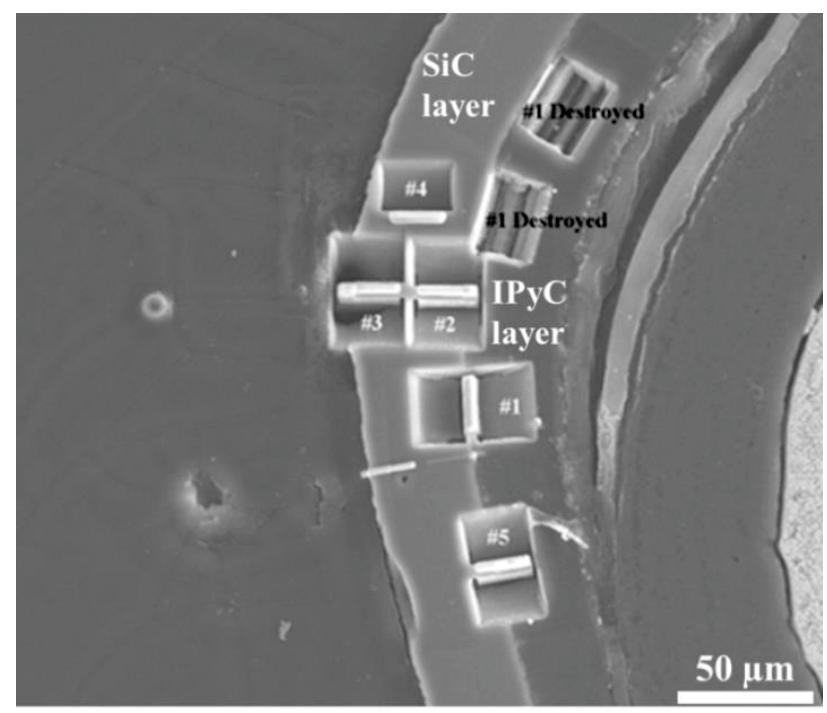

Figure 1 SEM image showing locations where TEM lamellae were sectioned by FIB.

\section{RESULTS AND DISCUSSION}

SEM results

The SEM montage and a low magnification SEM image of the whole particle cross section for AGR1-131-099 are displayed in Figure 2. In the SEM montage images, precipitate clusters located in the IPyC layer, the IPyC-SiC interlayer and the $\mathrm{SiC}$ layer are identified and labelled separately. The fission product precipitates are typically small, and the SEM has relatively low resolution. The magnification used for recording montage images was 4000x, and in SEM images, several precipitates close to each other may appear as one large cluster of precipitates. Precipitate clusters are found in various locations within the IPyC layer, IPyC-SiC interlayer, and $\mathrm{SiC}$ layer of the particle with a higher number density observed in the region of the interface in closer proximity to the kernel, or the left side of the particle. Large agglomerations of precipitate clusters are located in the upper left region of the particle cross section where the IPyC-SiC interface deviates from spherical contour and the interface is closest to the fuel kernel. In summary, precipitate clusters are found in various locations along the perimeter of the IPyC-SiC interface with a correlation between the distribution of precipitate clusters and the proximity of the IPyC-SiC interface to the fuel kernel. A slightly higher concentration of precipitate clusters is found in the region where the kernel is slightly closer to the IPyC-SiC interface. These results are very similar to those obtained from particles from other compacts [16].

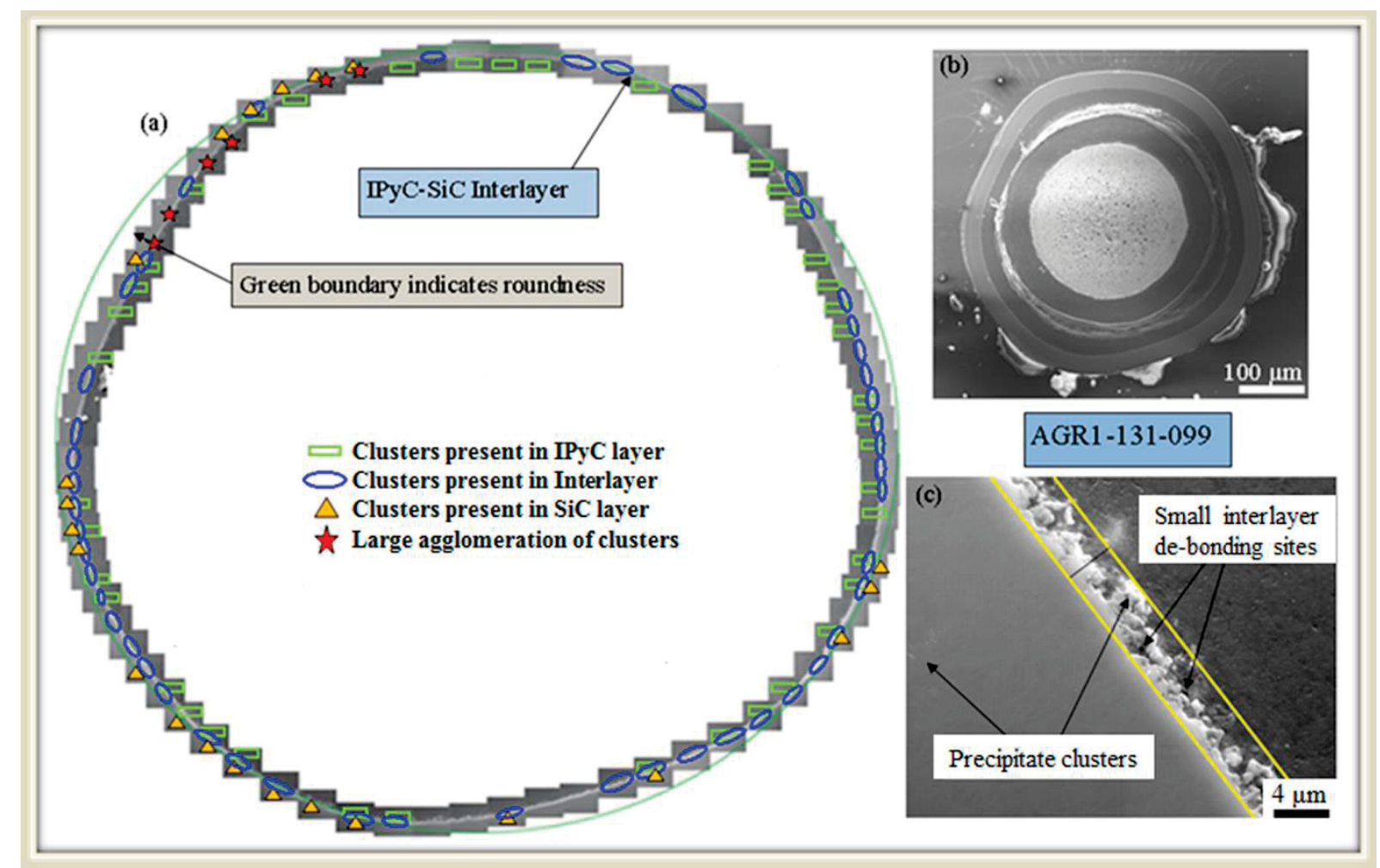

Figure 2. Particle AGR1-131-099 (a) SEM image montage depicting distribution of precipitate clusters, (b) SEM image of the particle cross-section at mid-plane, and (c) representative SEM image of the IPyC-SiC interface showing precipitate clusters at and near the interlayer 


\section{TEM results}

Figure 3 shows STEM and TEM images of TEM lamella 5. It is evident that there is a relatively low number density of precipitates at the IPyC-SiC interface and in the IPyC layer, compared to those in particles from other compacts $[12,16]$. In addition, the precipitates at the IPyC-SiC interface, mostly $<200 \mathrm{~nm}$ in diameter, are smaller than those in particles from other compacts $[12,16]$. The precipitates in the IPyC layer are $<50 \mathrm{~nm}$ in diameter. It should be noted that the relatively large precipitates close to the IPyC-SiC interface are mostly located in the SiC layer instead of in the IPyC layer, which is in contrast with the phenomenon observed in particles from other compacts [12, 16]. This observation may suggest that in Compact 1-3-1, the fission product precipitates have progressed more into the $\mathrm{SiC}$ layer compared to particles from other compacts. It is also noted that there are some pores at the IPyC$\mathrm{SiC}$ interface, which is not typical for particles from other compacts $[12,16]$. This phenomenon suggests degradation of the IPyC-SiC interface, which may have an adverse effect on retention of fission products. From the TEM image, the grain sizes in the $\mathrm{SiC}$ layer are mostly in the range of $0.2-0.5 \mu \mathrm{m}$, which are smaller than those in baseline fuel particles [12].
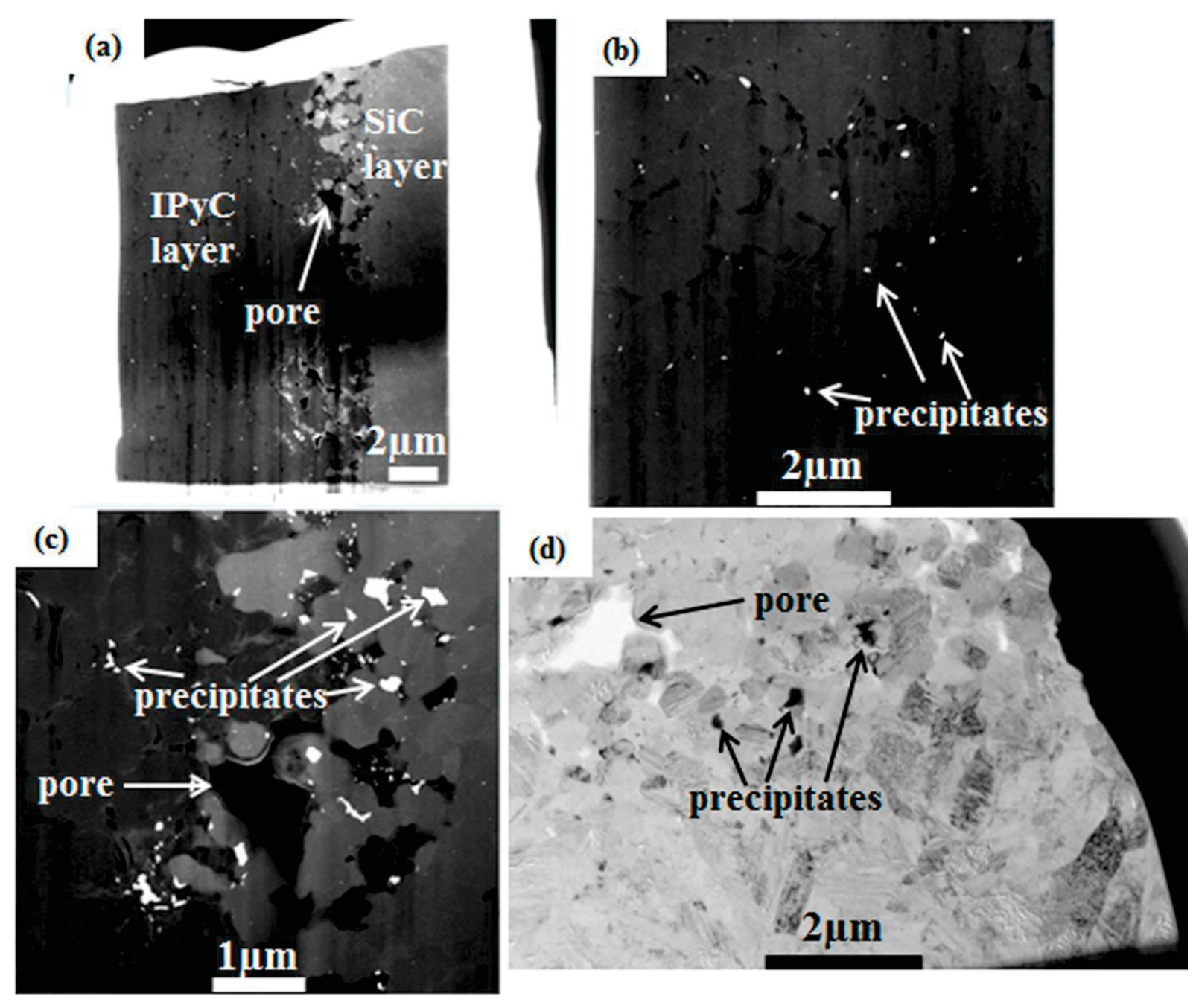

Figure 3 (a) (b) (c) STEM images of TEM lamella 5 showing the whole sample (a), the IPyC layer (b) and the IPyC-SiC interface (c); (d) TEM image of an area close to the IPyC-SiC interface 

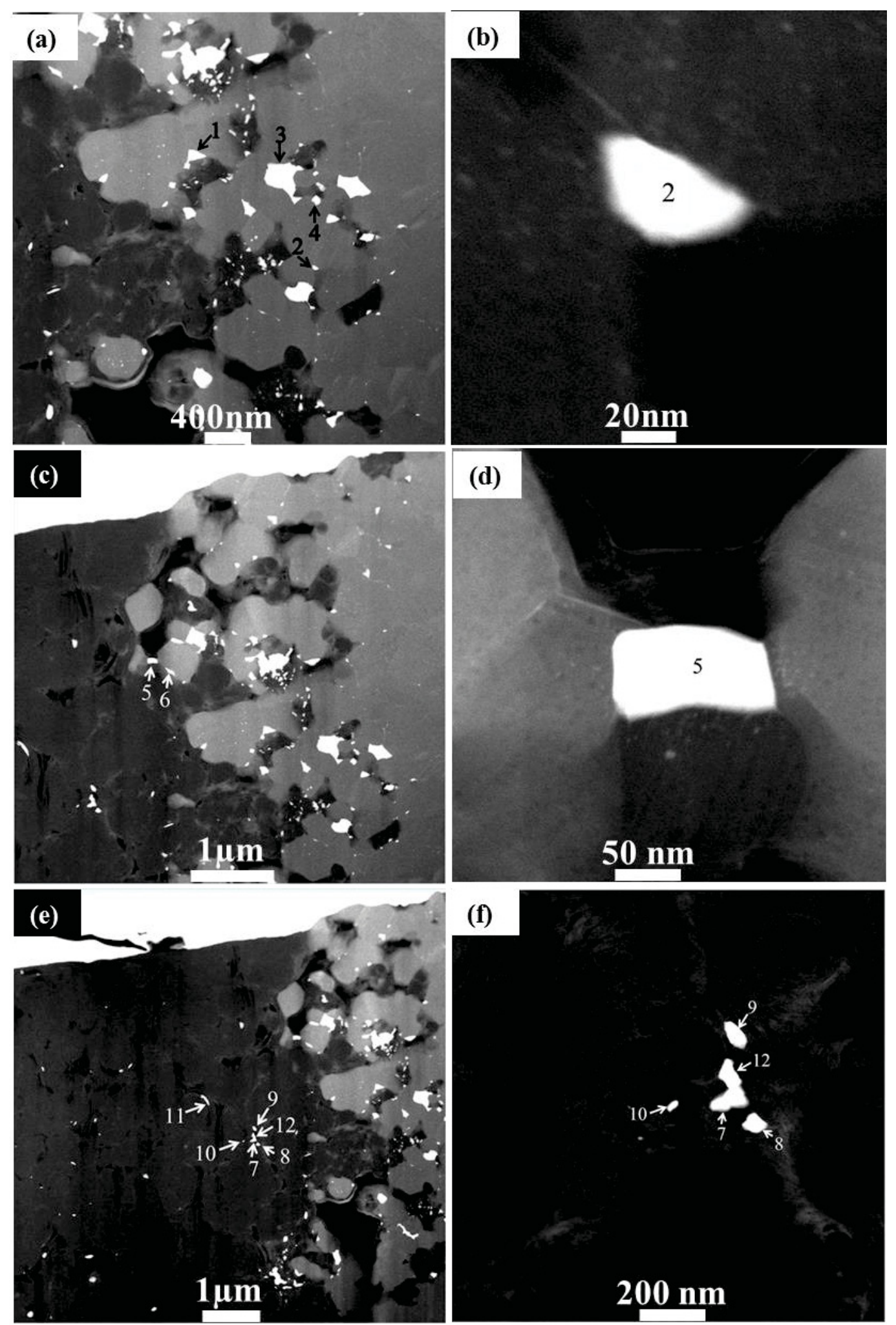

Figure 4 (a)-(f) STEM images of TEM lamella 5, the locations where selected EDS point scans were performed are indicated by arrows and numbers. These EDS point scans are representative in terms of precipitate compositions. (a) (c) (e) are low magnification images showing the locations of the investigated precipitates relative to the IPyC-SiC interface, and (b) (d) (f) are higher magnification images showing the exact precipitates on which EDS point scans were performed. 


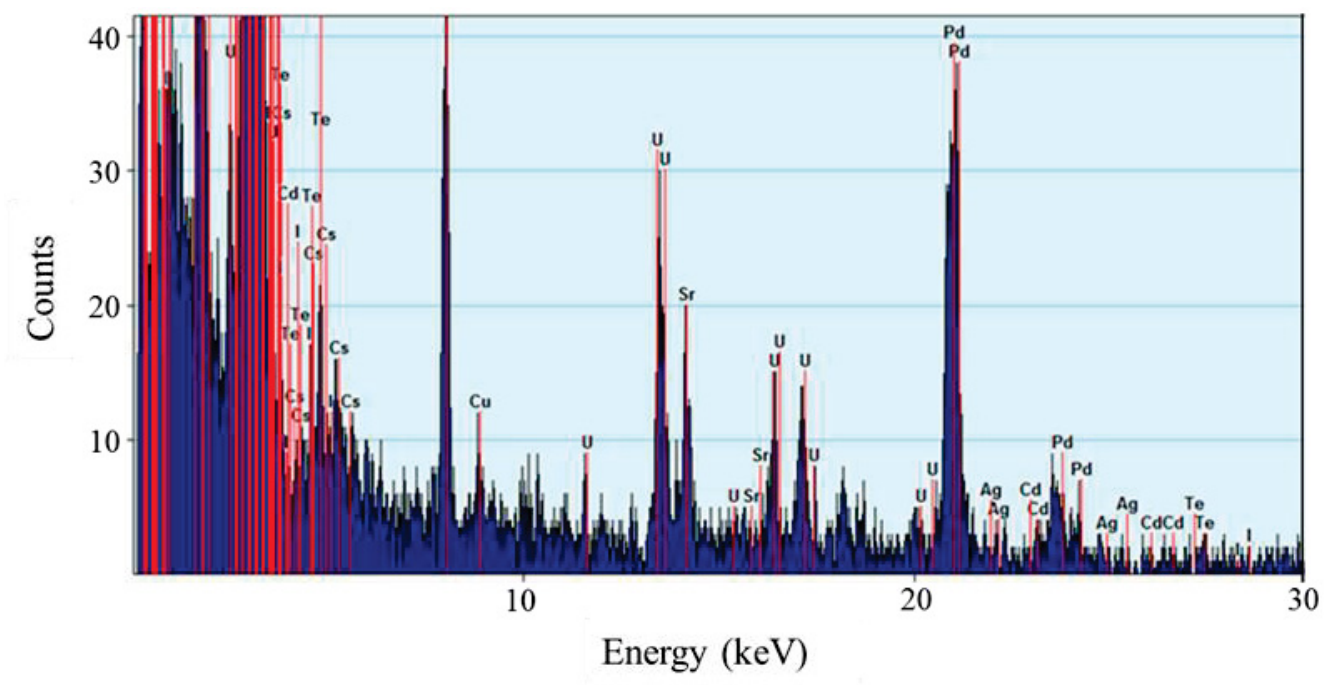

Figure 5 A representative EDS spectrum corresponding to point scan on precipitate 1 in Figure 4.

Table 1 Representative composition of precipitates in TEM lamella 5. These compositions correspond to precipitates indicated in Figure 4. All the compositions presented are raw data from EDS results. Concentration values below $\sim 0.5$ at.\% may be within background and are therefore not considered accurate. The actual presence of such elements needs further confirmation..

\begin{tabular}{|l|l|l|l|l|l|l|l|l|l|l|l|l|}
\hline Concentration (at.\%) & $\mathrm{C}$ & $\mathrm{O}$ & $\mathrm{Si}$ & $\mathrm{U}$ & $\mathrm{Pd}$ & $\mathrm{Cd}$ & $\mathrm{Ag}$ & $\mathrm{Cs}$ & $\mathrm{Ce}$ & $\mathrm{Sr}$ & $\mathrm{I}$ & $\mathrm{Te}$ \\
\hline Point scan 1 & 39.36 & 0.41 & 48.67 & 1.50 & 9.75 & 0.01 & 0.19 & 0 & 0 & 0.06 & 0 & 0 \\
\hline Point scan 2 & 60.49 & 0 & 33.75 & 5.03 & 0.59 & 0 & 0 & 0 & 0 & 0.12 & 0 & 0 \\
\hline Point scan 3 & 28.19 & 0 & 28.89 & 0.59 & 42.32 & 0 & 0 & 0 & 0 & 0 & 0 & 0 \\
\hline Point scan 4 & 78.30 & 0.14 & 17.99 & 3.55 & 0 & 0 & 0 & 0 & 0 & 0 & 0 & 0 \\
\hline Point scan 5 & 79.23 & 0 & 9.10 & 1.47 & 8.90 & 0.31 & 0 & 0.09 & 0.28 & 0.59 & 0 & 0 \\
\hline Point scan 6 & 8.13 & 1.16 & 79.34 & 8.63 & 0.89 & 0 & 0 & 0.34 & 0 & 0.69 & 0 & 0.78 \\
\hline Point scan 7 & 88.21 & 1.00 & 4.00 & 0 & 6.68 & 0 & 0 & 0.06 & 0 & 0.01 & 0 & 0 \\
\hline Point scan 8 & 96.47 & 0.30 & 0.46 & 1.63 & 0.03 & 0.85 & 0 & 0 & 0 & 0.16 & 0.02 & 0.04 \\
\hline Point scan 9 & 80.90 & 0.24 & 7.70 & 1.78 & 7.25 & 0.33 & 0 & 0 & 0.21 & 1.17 & 0.16 & 0.21 \\
\hline Point scan 10 & 96.37 & 0.43 & 0.64 & 2.15 & 0.10 & 0.13 & 0.10 & 0.01 & 0 & 0 & 0 & 0.02 \\
\hline Point scan 11 & 83.93 & 1.66 & 6.00 & 0.60 & 7.52 & 0.04 & 0.11 & 0.03 & 0.01 & 0.04 & 0 & 0 \\
\hline Point scan 12 & 82.97 & 0.21 & 7.97 & 1.19 & 7.36 & 0 & 0 & 0 & 0 & 0.28 & 0 & 0 \\
\hline
\end{tabular}

EDS point scans were performed on numerous precipitates at the IPyC-SiC interface, in the $\mathrm{SiC}$ layer and in the IPyC layer. Figure 4 display some precipitates in TEM lamella 5 with representative compositions. Note that for very small precipitates with diameters on the order of $20 \mathrm{~nm}$, EDS was performed at high magnification (e.g., $1 \mathrm{Mx}$ ), however, STEM images with relatively lower magnifications are shown in Figure 4 to demonstrate the distances of the precipitates from the IPyC-SiC interface. Compositions of the precipitates shown in Figure 4 are indicated in Table 1. Note that Precipitates 1-6 are in the $\mathrm{SiC}$ layer and close to the IPyC-SiC interface and that Precipitates 7-12 are in the IPyC layer and also close to the IPyC-SiC interface. It can be seen that precipitates in the $\mathrm{SiC}$ layer have the following types of compositions: Pd-Si-U, Pd-Si, $\mathrm{Pd}-\mathrm{U}, \mathrm{Pd}, \mathrm{U}$. Note that for EDS of precipitates in the $\mathrm{SiC}$ layer, the $\mathrm{SiC}$ matrix may contribute significantly to the EDS results, and the exact $\mathrm{Si}$ content in the precipitates cannot be determined. However, as a rough estimate, the Si concentration in the precipitates is calculated by subtracting the $\mathrm{C}$ concentration from the $\mathrm{Si}$ concentration in the EDS result, assuming that the $\mathrm{SiC}$ is ideally stoichiometric and $\mathrm{Si}$ and $\mathrm{C}$ concentrations contributed from the $\mathrm{SiC}$ matrix are exactly identical. If in the EDS result, the Si concentration is smaller than $\mathrm{C}$ concentration, it is interpreted that there is no $\mathrm{Si}$ in the precipitate. It should be emphasized, however, that all the compositions presented in this paper are raw data from EDS results, without the attempt to exclude the contribution from the matrix. From the EDS results, it can be seen that large precipitates $(\sim 0.1-0.3 \mu \mathrm{m})$ at the IPyC-SiC interface are typically $\mathrm{Pd}-\mathrm{Si}-\mathrm{U}$. However, there are exceptions. For example, precipitate 3 in Figure 4 is large $(\sim 0.2-0.3 \mu \mathrm{m})$, but it mostly contains $\mathrm{Pd}$ with a little $\mathrm{U}$. Note that precipitate 1 , a Pd-Si-U precipitate, contains 0.19 at.\% Ag. Since the Ag concentration is very low and close to or even lower than the detection limit 
of EDS (from the EDS spectrum shown in Figure 5, the Ag peaks are close to the background), it is hard to conclude that this precipitate actually contains Ag. Similarly, precipitate 5 is $\mathrm{Pd}-\mathrm{U}$ with a measured cadmium $(\mathrm{Cd})$ concentration of only 0.31 at. $\%$, however, the presence of $\mathrm{Cd}$ cannot be confirmed due to the very low concentration. It is noted that the nanosized ( 20-50 $\mathrm{nm}$ in diameter) precipitates 2 and 4 mostly contain U. From the EDS results, it can be seen that precipitates in the IPyC layer have the following types of compositions: Pd$\mathrm{Si}-\mathrm{U}, \mathrm{Pd}-\mathrm{Si}, \mathrm{U}-\mathrm{Si}$, and U. Pd-U and Pd precipitates existing in the $\mathrm{SiC}$ layer are not present in the IPyC layer, which is likely due to the relatively rapid diffusion of $\mathrm{Pd}$ in the IPyC and the $\mathrm{SiC}$ layers. Precipitates mostly containing $\mathrm{U}$ are frequently observed in the IPyC layer. It is distinct that U-Si precipitates are found in the IPyC layer, which was not observed in the coating layers of particles from other compacts. From the U-Si phase diagram, U-Si compounds do exist. It is noted that Pd-Si$\mathrm{U}$ precipitates (e.g. precipitate 12) in the IPyC layer are only $\sim 50 \mathrm{~nm}$ in diameter, even if they are very close to the IPyC-SiC interface.

STEM and TEM images of TEM lamella 2 are shown in Figure 6. From the STEM images, it can be seen that a network of small precipitates (bright spots in the images) are present in the $\mathrm{SiC}$ layer. Based on the TEM image, the grain diameters in the $\mathrm{SiC}$ layer are on the order of $500 \mathrm{~nm}$. Grain sizes increase from the inner to the outer region of the $\mathrm{SiC}$ layer, with increased distance from the IPyC-SiC interface.
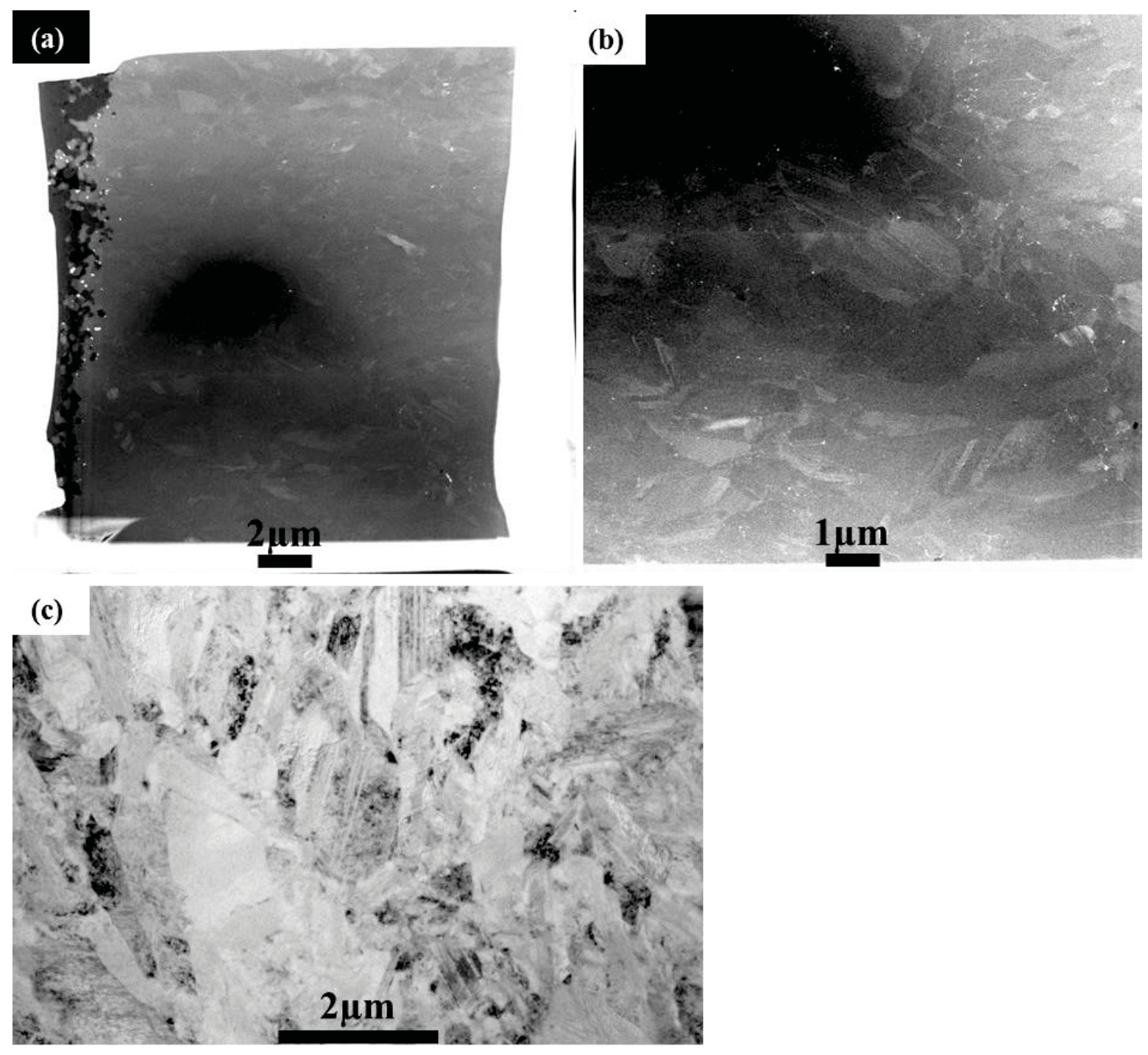

Figure 6 (a) (b) STEM images of TEM lamella 2 with different magnifications showing the whole sample (a), and part of the sample (b); (c) TEM image of a selected area. 

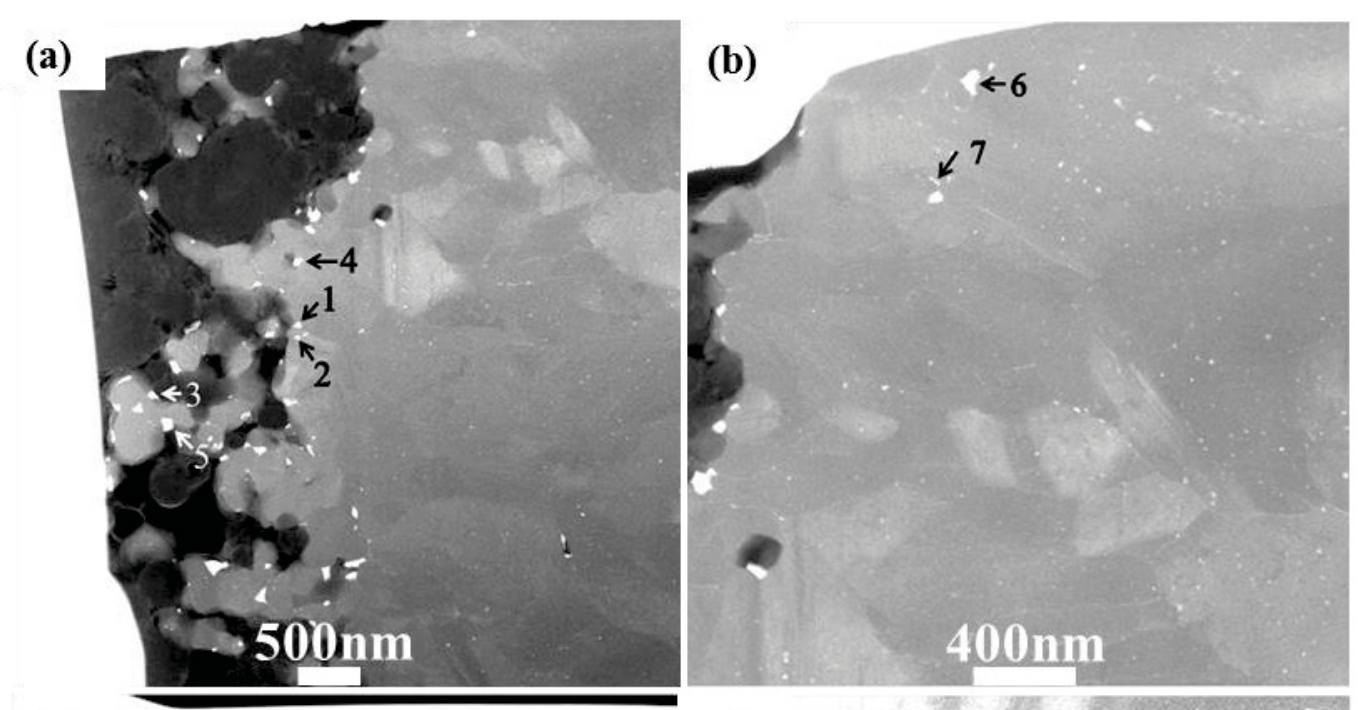

(c)
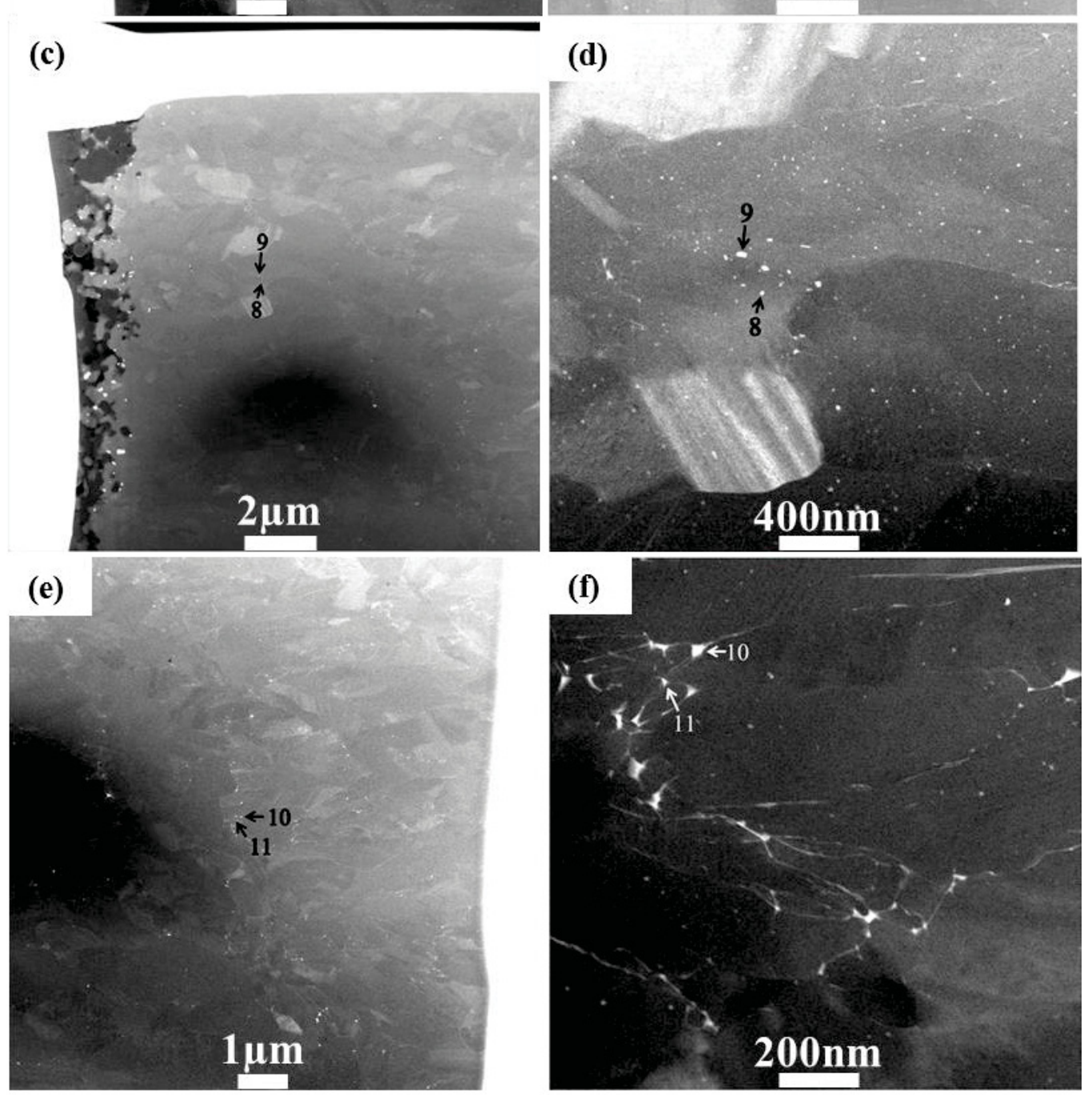

Figure 7 STEM images of TEM lamella 2, the locations where selected EDS point scans were performed are indicated by arrows and numbers. (a) (b) (c) (e) are low magnification images showing the locations of the investigated precipitates relative to the IPyC-SiC interface, and (d) (f) are higher magnification images showing the exact precipitates on which EDS point scans were performed. 
Table 2 Representative compositions of precipitates in TEM lamella 2. These compositions correspond to precipitates indicated in Figure 7. All the compositions presented are raw data from EDS results. Concentration values below $\sim 0.5$ at.\% may be within background and are therefore not considered accurate. The actual presence of such elements needs further confirmation.

\begin{tabular}{|l|l|l|l|l|l|l|l|l|l|l|l|l|}
\hline Concentration (at.\%) & $\mathrm{C}$ & $\mathrm{O}$ & $\mathrm{Si}$ & $\mathrm{U}$ & $\mathrm{Pd}$ & $\mathrm{Cd}$ & $\mathrm{Ag}$ & $\mathrm{Cs}$ & $\mathrm{Ce}$ & $\mathrm{Sr}$ & $\mathrm{I}$ & $\mathrm{Te}$ \\
\hline Point scan 1 & 34.60 & 0.14 & 58.06 & 1.17 & 5.63 & 0.11 & 0.12 & 0 & 0.12 & 0 & 0 & 0 \\
\hline Point scan 2 & 46.55 & 0.40 & 51.96 & 1.03 & 0.02 & 0 & 0 & 0 & 0 & 0 & 0.01 & 0 \\
\hline Point scan 3 & 90.18 & 0.33 & 7.98 & 1.47 & 0 & 0 & 0 & 0.02 & 0 & 0 & 0 & 0 \\
\hline Point scan 4 & 42.58 & 0.09 & 50.50 & 1.20 & 5.54 & 0 & 0 & 0 & 0.01 & 0.05 & 0 & 0 \\
\hline Point scan 5 & 57.55 & 0.28 & 34.26 & 1.09 & 6.47 & 0 & 0 & 0.03 & 0.06 & 0.21 & 0 & 0 \\
\hline Point scan 6 & 31.79 & 0.97 & 56.47 & 0.26 & 10.43 & 0 & 0.05 & 0 & 0 & 0 & 0 & 0 \\
\hline Point scan 7 & 41.09 & 0 & 54.70 & 0 & 4.20 & 0 & 0 & 0 & 0 & 0 & 0 & 0 \\
\hline Point scan 8 & 37.79 & 0 & 54.04 & 0 & 8.02 & 0.05 & 0.07 & 0 & 0 & 0 & 0 & 0 \\
\hline Point scan 9 & 20.81 & 0.92 & 68.19 & 0 & 9.58 & 0.20 & 0 & 0 & 0 & 0 & 0.09 & 0.16 \\
\hline Point scan 10 & 53.38 & 0.14 & 37.34 & 0 & 9.11 & 0 & 0 & 0.01 & 0 & 0 & 0 & 0 \\
\hline Point scan 11 & 60.24 & 0.19 & 36.18 & 0.19 & 3.18 & 0 & 0 & 0 & 0 & 0 & 0 & 0 \\
\hline
\end{tabular}

EDS point scans were also conducted on numerous precipitates in the SiC layer in TEM lamella 2. Figure 7 show precipitates with representative compositions, and Table 2 indicates the compositions of the precipitates labelled in Figure 6 on which EDS point scans were performed. From STEM images in Figures 7(b), 7(d) and 7(f), it is evident that an extensive network of small precipitates are present in the $\mathrm{SiC}$ layer, both at the grain boundaries (GBs) and inside grain interiors. Precipitates at the GBs are generally larger than those inside grain interiors. Note that precipitates 1-5 are almost right at the IPyC-SiC interface, and precipitates 6-7 are $\sim 500 \mathrm{~nm}$ away from the IPyC-SiC interface, and precipitates $8-9$ are $\sim 2.5$ $\mu \mathrm{m}$ from the interface, and precipitates $10-11$ are $\sim 9 \mu \mathrm{m}$ from the interface. From the EDS results, precipitates in the $\mathrm{SiC}$ layer have the following types of compositions: $\mathrm{Pd}-\mathrm{Si}-\mathrm{U}, \mathrm{Pd}-\mathrm{Si}$, $\mathrm{Pd}-\mathrm{U}, \mathrm{Pd}, \mathrm{U}$, and U-Si. It should be noted that only a few precipitates inside grain interiors were analyzed by EDS, and these precipitates contain only Pd. The precipitate compositions found in TEM lamella 2 are very similar to those observed in the $\mathrm{SiC}$ layer of TEM lamella 5, except that U-Si precipitates are found in the former instead of the latter. Note that precipitate 2, a U-Si precipitate is in the $\mathrm{SiC}$ layer and very close to the IPyC-SiC interface. With increased distance from the IPyC-SiC interface, there is a trend for the change in precipitate composition in the $\mathrm{SiC}$ layer: the precipitates close to the IPyC-SiC interface are mostly Pd-Si-U, Pd-U, U or U-Si; Pd-Si precipitates prevail in the locations $\sim 0.5-7 \mu \mathrm{m}$ from the interface; and precipitates $>7 \mu \mathrm{m}$ from the interface are dominantly $\mathrm{Pd}$, although a small fraction of the precipitates are $\mathrm{Pd}-\mathrm{U}$. That is, with increased distance from the IPyC-SiC interface, the number density of U-containing precipitates is decreased. In addition, with increased distance from the IPyC$\mathrm{SiC}$ interface, the sizes of precipitates are generally decreased. The Pd precipitates $>7 \mu \mathrm{m}$ from the interface are mostly $<20$ $\mathrm{nm}$ in diameter, and those inside grain interiors are generally a few nanometers in diameter. Essentially no Ag-containing precipitates are identified, which is consistent with the 0.15 fraction of $\mathrm{Ag}$ retention in this TRISO coated particle. The yield of $\mathrm{Ag}$ fission product is only $\sim 1 / 20$ that of Pd in terms of mass, and since the fraction of Ag retention is very low, it is anticipated that the probability of finding Ag by STEM-EDS is very low.

STEM and TEM images of TEM lamella 3 are displayed in Figure 8. Only a low number density of precipitates is evident from the low-magnification STEM image. From the TEM image, the grain diameters in the $\mathrm{SiC}$ layer are on the order of 2 $\mu \mathrm{m}$.

Numerous precipitates in the $\mathrm{SiC}$ layer in TEM lamella 3 were also analyzed using EDS point scans. Figure 9 display precipitates with representative compositions, and Table 3 indicates the compositions of the precipitates labelled in Figure 9 on which EDS point scans were performed. Note that in Figures 9(a) and 9(e), from left to right, the distance from the IPyC-SiC interface is increased. Therefore, in Figure 8, precipitates 5 and 6 are closest to the $\mathrm{IPyC}-\mathrm{SiC}$ interface, and precipitates 1 and 2 are farthest from the interface, and precipitates 3 and 4 are in the middle. From Figure 1, the end of TEM lamella 3 closest to the IPyC-SiC interface is $\sim 18 \mu \mathrm{m}$ from the interface, and the farthest end is $\sim 36 \mu \mathrm{m}$ from the interface. In Figure 9(e), a network of precipitates is still evident, however, precipitates are generally at GBs, with few inside grain interiors; the largest precipitates at GBs are still $\sim 100 \mathrm{~nm}$ in diameter. In Figure 9(b), the network of precipitates is less evident, and the largest precipitates at GBs are $\sim 80 \mathrm{~nm}$ in diameter. To summarize, in TEM lamella 3, with increased distance from the IPyC-SiC interface, the network of precipitates become less evident, and the precipitates are generally at GBs, and the precipitates become smaller; however, the GB precipitates can still be $\sim 80-100 \mathrm{~nm}$ in diameter. From the EDS results, precipitates in TEM lamella 3 have the following types of compositions: Pd-Si-U, and Pd-Si. It should be noted that only 29 precipitates in this TEM lamella were subjected to EDS measurements, and that these precipitates investigated are generally relatively large, since 
there is a relatively low number density of precipitates in this TEM lamella, and naturally it was easier to find relatively large precipitates and then perform EDS on these precipitates. It is anticipated that those smaller precipitates in this TEM lamella are mostly $\mathrm{Pd}$, based on the results from TEM lamella 2 . However, it is distinct that even in TEM lamella 3 that is $\sim 18$ $36 \mu \mathrm{m}$ from the IPyC-SiC interface, $\mathrm{Pd}-\mathrm{Si}-\mathrm{U}$ and $\mathrm{Pd}-\mathrm{Si}$ precipitates were still found, which are generally those large precipitates at GBs. The presence of Pd-Si precipitates nearly across the entire $\mathrm{SiC}$ layer indicates that there may be interactions between $\mathrm{Pd}$ and $\mathrm{SiC}$ across the whole $\mathrm{SiC}$ layer, however, such interactions are limited in degree, and there is no significant corrosion of $\mathrm{SiC}$ by $\mathrm{Pd}$. Meanwhile, it should be emphasized that the presence of $\mathrm{Si}$ in these precipitates needs to be confirmed by another technique that is more accurate in composition measurement, because of the contribution of the $\mathrm{SiC}$ matrix to the EDS results. The presence of Pd-Si-U precipitates nearly across the entire $\mathrm{SiC}$ layer indicates migration of $\mathrm{U}$ almost across the entire $\mathrm{SiC}$ layer (a)

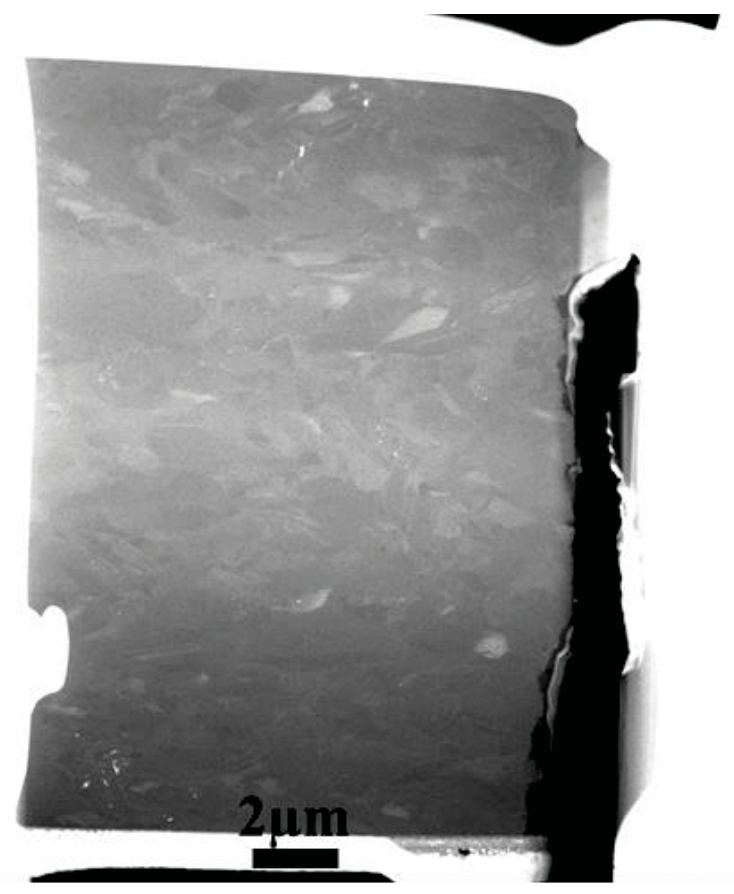

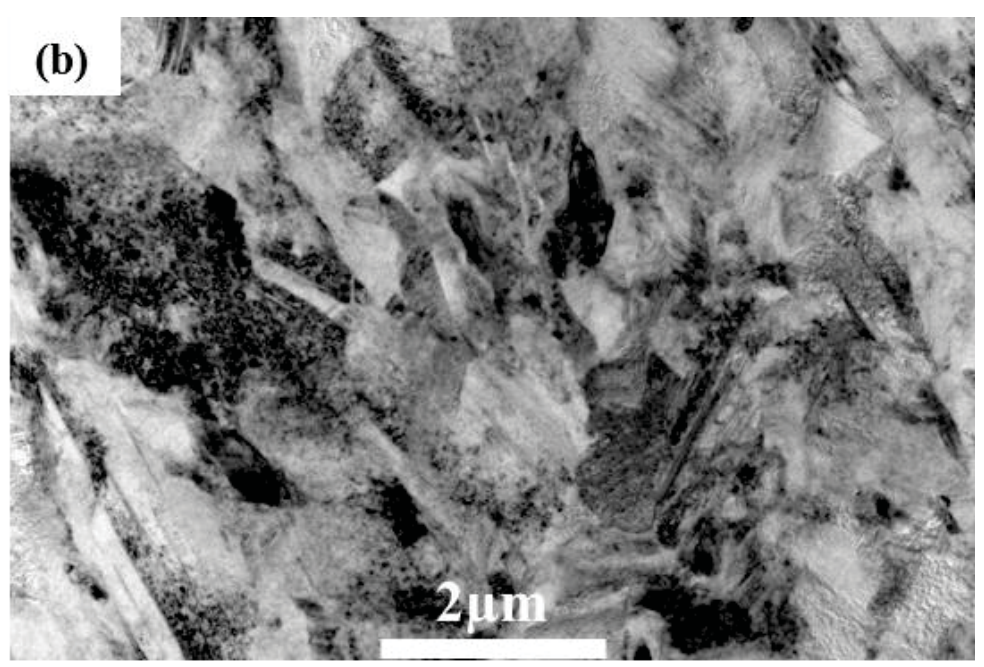

Figure 8 (a) STEM image of TEM lamella 3 showing the whole sample; (b) TEM image of a selected area. 

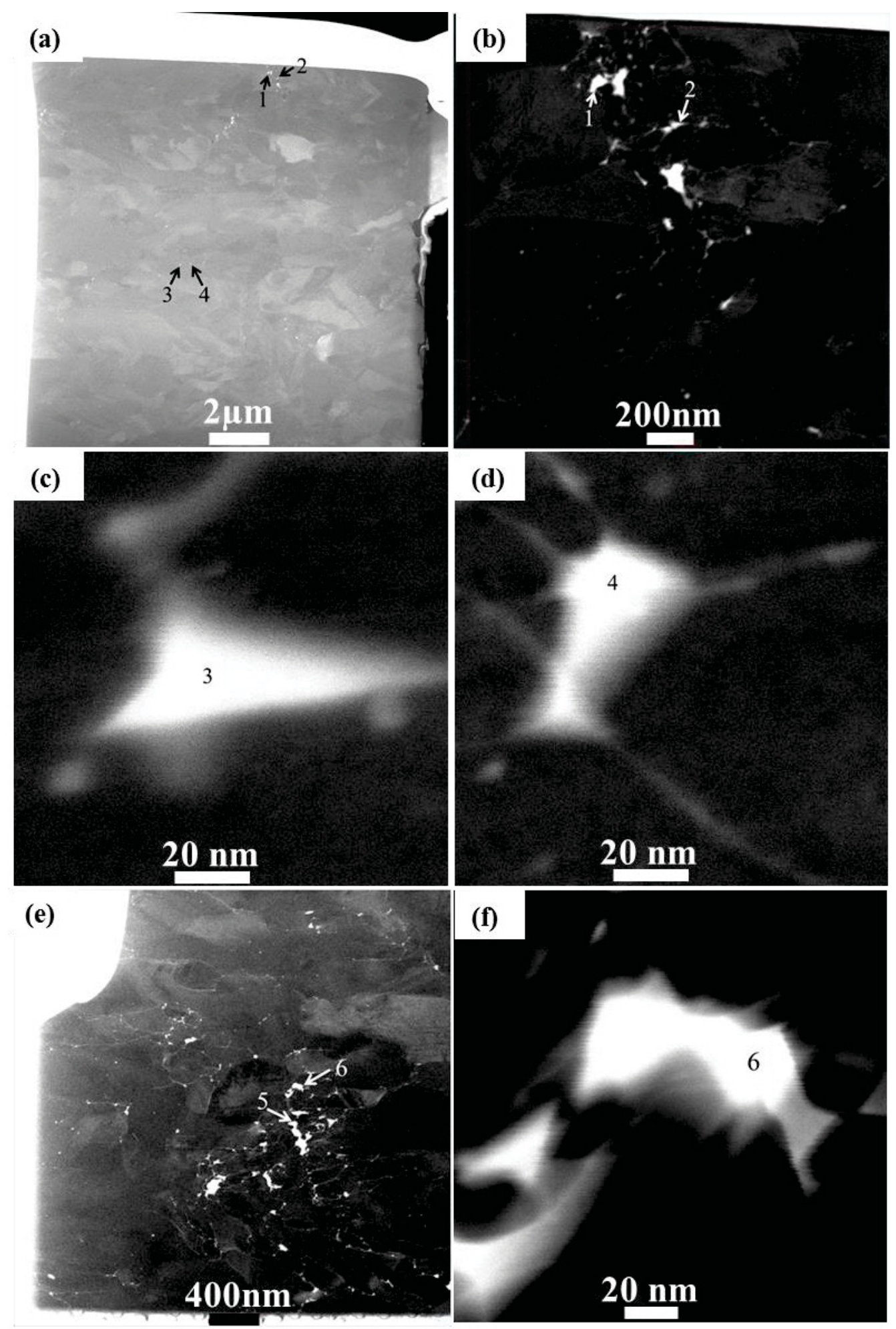

Figure 9 STEM images of TEM lamella 3, the locations where selected EDS point scans were performed are indicated by arrows and numbers. (a) (e) are low magnification images showing the locations of the investigated precipitates relative to the IPyC-SiC interface, and (b) (c) (d) (f) are higher magnification images showing the exact precipitates on which EDS point scans were performed. 
Table 3 Representative compositions of precipitates in TEM lamella 3. These compositions correspond to precipitates indicated in Figure 9. All the compositions presented are raw data from EDS results. Concentration values below $\sim 0.5$ at. $\%$ may be within background and are therefore not considered accurate. The actual presence of such elements needs further confirmation.

\begin{tabular}{|l|l|l|l|l|l|l|l|l|l|l|l|l|}
\hline Concentration (at.\%) & $\mathrm{C}$ & $\mathrm{O}$ & $\mathrm{Si}$ & $\mathrm{U}$ & $\mathrm{Pd}$ & $\mathrm{Cd}$ & $\mathrm{Ag}$ & $\mathrm{Cs}$ & $\mathrm{Ce}$ & $\mathrm{Sr}$ & $\mathrm{I}$ & $\mathrm{Te}$ \\
\hline Point scan 1 & 27.73 & 0 & 59.45 & 4.27 & 8.20 & 0 & 0 & 0 & 0.02 & 0.30 & 0 & 0 \\
\hline Point scan 2 & 29.26 & 0.04 & 63.43 & 0 & 7.23 & 0 & 0.02 & 0 & 0 & 0 & 0 & 0 \\
\hline Point scan 3 & 22.86 & 0.15 & 72.43 & 0 & 4.52 & 0 & 0.02 & 0 & 0 & 0 & 0 & 0 \\
\hline Point scan 4 & 21.71 & 0 & 73.18 & 1.11 & 3.99 & 0 & 0 & 0 & 0 & 0 & 0 & 0 \\
\hline Point scan 5 & 35.65 & 0.36 & 55.44 & 2.30 & 6.18 & 0 & 0 & 0 & 0 & 0.05 & 0 & 0 \\
\hline Point scan 6 & 32.14 & 1.14 & 49.41 & 0 & 17.28 & 0 & 0 & 0 & 0 & 0 & 0 & 0 \\
\hline
\end{tabular}

\section{CONCLUSIONS}

A selected coated particle, AGR-131-099, was subjected to SEM, TEM and STEM-EDS investigations. SEM results indicate a correlation between the distribution of fission product precipitates and the proximity of the IPyC-SiC interface to the fuel kernel. From TEM and STEM results, there are some pores at the IPyC-SiC interface of AGR-131-099, suggesting degradation of the IPyC-SiC interface. Based on EDS results, precipitates in the $\mathrm{SiC}$ layer have the following types of compositions: Pd-Si-U, Pd-Si, Pd-U, Pd, U, U-Si, and precipitates in the IPyC layer have the following types of compositions: $\mathrm{Pd}-\mathrm{Si}-\mathrm{U}, \mathrm{Pd}-\mathrm{Si}, \mathrm{U}-\mathrm{Si}, \mathrm{U}$. The presence of $\mathrm{Si}$ in the precipitates in the $\mathrm{SiC}$ layer needs further confirmation, due to the limitation of the EDS technique. No Ag-containing precipitates are evident in the IPyC or $\mathrm{SiC}$ layers, consistent with the high Ag release of this particle. With increased distance from the IPyC-SiC interface, the number of Ucontaining precipitates is decreased; however, such precipitates are present nearly across the entire $\mathrm{SiC}$ layer.

\section{ACKNOWLEDGMENTS}

This work was sponsored by the U.S. Department of Energy, Office of Nuclear Energy, under DOE Idaho Operations Office Contract DE-AC07-05ID14517. James Madden is acknowledged for the FIB sample preparation.

\section{REFERENCES}

[1] P.A. Demkowicz, J.D. Hunn, R.N. Morris, J.M. Harp, P.L. Winston, C.A. Baldwin, F.C. Montgomery, "Preliminary results of post-irradiation examination of the AGR-1 TRISO fuel compacts", Paper HTR2012-3-021, in: Proceedings of the HTR 2012, Tokyo, Japan, October 28-November 1, 2012.

[2] J.J. Powers, B.D. Wirth, "A review of TRISO fuel performance models," Journal of Nuclear Materials, 405 (2010) $74-82$.

[3] J. Engelhard, K. Krüger, H, Gottaut, "Investigations of the Impurities and Fission Products in the AVR Coolant at an Average Hot Temperature of $950^{\circ} \mathrm{C}$," Nuclear Engineering Design, 34, p. 85, 1975.

[4] H. Nabielek, P.E. Brown, P. Offerman, "Silver Release from Coated Particle Fuel”, Nuclear Technology, 35, pp. 483, 1977.

[5] K. Minato, T. Ogawa, K. Fukuda, H. Sekino, H. Miyanishi, S. Kado, I. Takahashi, "Release Behavior of Metallic Fission
Products from HTGR Fuel Particles at 1600 to $1900^{\circ} \mathrm{C}$," Journal of Nuclear Materials, 202, p. 47, 1993.

[6] I.J. van Rooyena, M.L. Dunzik-Gougar, P.M. van Rooyen, "Silver (Ag) transport mechanisms in TRISO coated particles: A critical review," Nuclear Engineering and Design, 271 (2014) 180-188.

[7] I. J. van Rooyen, H. Nabielek, J. H Neethling, M. J. Kania, D. A. Petti, "Progress in Solving the Elusive Ag Transport Mechanism in TRISO Coated Particles: "What is new?", Paper 3-1261, 7th International Topical Meeting On High Temperature Reactor Technology (HTR 2014), Weihai, China, October 27-31, 2014.

[8] I.J. van Rooyen T. M. Lillo, Y. Q. Wu, "Identification of Silver and Palladium in Irradiated TRISO Coated Particles of the AGR-1 Experiment," Journal of Nuclear Materials, 446 (2014) 178-186.

[9] T.N. Tiegs, "Fission Product Pd-SiC Interaction in Irradiated Coated-Particle Fuels," Nuclear Technology, 57, p. 389, 1972.

[10] R.J. Lauf, T.B. Lindemer, R.L. Pearson, Out-of-Reactor Studies of Fission Product-Silicon Carbide Interactions in HTGR Fuel Particles, Journal Nuclear Materials, 120, p. 6, 1984.

[11] K. Minato, T. Ogawa. S. Kashimura, K. Fukuda, M. Shimizu, Y. Tayama, I. Takahashi, "Fission Product PalladiumSilicon Carbide Interaction in HTGR Fuel Particles," Journal of Nuclear Materials, 172, p. 184, 1990.

[12] I.J. van Rooyen, DE Janney, BD Miller, PA Demkowicz, J. Riesterer, "Electron Microscopic Evaluation and Fission Product Identification of Irradiated TRISO Coated Particles from the AGR 1 Experiment," A Preliminary Review, Nuclear Engineering and Design, 271 (2014) 114-122.

[13] O'Connell, J.H. and Neethling J.H., "Ag Transport in High Temperature Neutron Irradiated 3C-SiC", J. Nucl. Mater. 455, 20-25 (2014).

[14] I.J. van Rooyen, E.J. Olivier and J.H Neethling, "Investigation of the Fission Products Silver, Palladium and Cadmium in Neutron Irradiated $\mathrm{SiC}$ using a Cs Corrected HRTEM", Paper 3-1255, 7th International Topical Meeting On High Temperature Reactor Technology (HTR 2014), Weihai, China, October 27-31, 2014.

[15] P. A. Demkowicz, J.M. Harp, P. L. Winston, S. A. Ploger, I. J. van Rooyen, B. D. Miller, J. Reisterer, “AGR-1 Compact 4-1-1 Post-Irradiation Examination”, Draft report. 
[16] I.J. van Rooyen, H.M. Wen, C. Hill, T.L. Trowbridge, "Scanning Electron Microscopic Examination of Irradiated TRISO Coated Particles of Compacts 4-1-1, 5-3-1, 1-3-1 and Safety Tested Compact 4-3-3 of AGR-1 Experiment", Draft report. 